\title{
Sn/C Composite as Anode Material for Lithium-Ion Batteries with Humic Acid as Carbon Source
}

\author{
Shuzhen Yang ${ }^{1}$, Yanfang Huang ${ }^{1}$, Guihong Han ${ }^{1, *}$, Jiongtian Liu $^{l}$, Yijun Cao ${ }^{2}$ \\ ${ }^{1}$ School of Chemical Engineering and Energy, Zhengzhou University, Zhengzhou 450001, P. R. \\ China. \\ ${ }^{2}$ Henan Province Industrial Technology Research Institure of Resources and Materials, Zhengzhou \\ University, Zhengzhou 450001, P. R. China. \\ *E-mail: guihong-han@hotmail.com
}

doi: $10.20964 / 2018.10 .21$

Received: 8 June 2018 / Accepted: 13 July 2018 / Published: 1 September 2018

$\mathrm{Sn} / \mathrm{C}$ anode materials were synthesized from $\mathrm{SnO}_{2}$ particles with humics as carbon source for coating with a simple solid-phase-reduction strategy. XRD and SEM show that the materials consist of Sn and C, with Sn completely encapsulated by carbon. The carbon film can accommodate the volume expansion of Sn particles and considerably improve the electrical conductivity of the anode. The Sn/C anode materials have initial specific capacities of 1215 and $556 \mathrm{mAh} \cdot \mathrm{g}^{-1}$ in the first discharge and charge $\left(100 \mathrm{~mA} \cdot \mathrm{g}^{-1}\right)$, respectively. The discharge capacity is $387 \mathrm{mAh} \cdot \mathrm{g}^{-1}$ after 50 cycles (coulombic efficiency $=98.2 \%$ ). Electrochemical impedance spectroscopy (EIS) indicates that the Sn/C prepared from humics as carbon source has markedly improved charge-transfer kinetics compared with Sn/C-s anode (having sucrose as carbon source). Humics can be considered as a highly advantageous carbon source for coatings to enhance the electrochemical performance of Sn-based anode for lithium-ion batteries.

Keywords: Sn/C; Humics; Carbon coating; Anode; Lithium-ion battery

\section{FULL TEXT}

(C) 2018 The Authors. Published by ESG (www.electrochemsci.org). This article is an open access article distributed under the terms and conditions of the Creative Commons Attribution license (http://creativecommons.org/licenses/by/4.0/). 